\title{
FORENSIC MEDICAL CRITERIA OF DIFFERENTIAL DIAGNOSIS OF ALCOHOL AND CARBON MONOXIDE POISONING BY USING AZIMUTHAL-INVARIANT POLARIZATION MUELLER-MATRIX MICROSCOPY
}

\author{
Olexandr Harazdiuk ${ }^{1}$, Ihor Ivaskevich ${ }^{2}$, Oleh Vanchuliak ${ }^{3}$, Yuliia Sarkisova ${ }^{4}$
}

\begin{abstract}
:
Introduction: Fatal intoxications with alcohol and carbon monoxide are the most common causes of poisoning that occur in forensic medical practice. Therefore, the differential diagnosis of these intoxications is extremely important. To solve this problem, we propose the use of the method of azimuthal-invariant polarization Mueller-matrix microscopy of histological sections of biological tissues (BT).

Objectives: The purpose of the study was to establish statistically significant criteria for differentiation of the cause of death in case of alcohol poisoning (AP) and carbon monoxide poisoning (CMP) by using azimuthal-invariant polarization Muellermatrix microscopy of polycrystalline fractions of histological sections of organs and blood films of the human body.

Results: A number of characteristic features have been identified that have not been previously described and allow to objectively differentiate the cause of death in the case of AP and CMP, namely $E k-0.95 \pm 0.045$ and $1.81 \pm 0.092$ in the study of histological sections of the myocardium; $E k-0,19 \pm 0,011$ and 1,11 $\pm 0,094$ - polycrystalline blood films. Analysis of the obtained data revealed a good level of accuracy in the study of histological sections of the myocardium (As 85\%) and polycrystalline blood films (As $88 \%$ ).

Conclusion: Thus, developed and tested method of azimuthal-invariant polarization Mueller-matrix microscopy allows to differentiate the cause of death in cases of AP and CMP.
\end{abstract}

UDC Classification: 616-091, DOI: https://doi.org/10.12955/pmp.v2.168

Keywords: differentiation, carbon monoxide poisoning, alcohol poisoning, polarization, laser polarimetry.

\section{Introduction}

In forensic practice, the most common toxic substances that can cause death are ethyl alcohol and carbon monoxide. These poisonings often occur in many countries around the world (Moon et al., 2020; Sircar et al., 2015). However, forensic experts in their daily practice face certain difficulties in diagnosing ethanol and CO poisoning, which are primarily due to the lack of specific morphological manifestations. All this complicates the diagnosis and leads to the fact that the determination of a toxic substance in the victim's body, especially when setting limit values, in many cases cannot serve as an unconditional guarantee for the diagnosis of death from poisoning. (Simonsen, et al., 2019; Kim et al., 2018; Rose et al., 2017).

The main diagnostic methods in a practical forensic examination are laboratory detection of alcohol and CO in blood and urine. However, the analysis of the results should also take into account the redox processes in the body, which significantly depend on the level of metabolism in different circumstances: significantly slowed down in the elderly and increased sharply with fever and cold. Also, often in the blood of the dead, the content of carboxyhemoglobin does not correspond to lethal concentrations. This can be due to a number of factors: temperature, humidity, wind speed, atmospheric pressure fluctuations, the presence of inhaled air, nitrogen oxides, gasoline vapors, carbon dioxide.

Therefore, in addition to forensic chemical research, it is advisable to use additional clarifying methods that can establish the presence of a toxic substance and determine the impact of the latter on the development of lethal outcomes.

In recent years, scientists have focused on the use of modern digital diagnostic methods that provide high accuracy and reproducibility of the results. Laser polarimetric methods of microscopic examination of optically inhomogeneous biological structures have become a new branch of such research. According to research Ushenko OG (2015), these techniques provide the most complete information about the architectonics of all BT of the human body, including the ability to detect any changes in case of various pathological conditions.

\footnotetext{
${ }^{1}$ Bukovinian State Medical University, Internal Medicine and Infectious Diseases Department, Chernivtsi, Ukraine, olexandr.harazdiuk@gmail.com

2 Bukovinian State Medical University, Forensic Medicine and Medical Law Department, Chernivtsi, Ukraine

${ }^{3}$ Bukovinian State Medical University, Forensic Medicine and Medical Law Department, Chernivtsi, Ukraine

${ }^{4}$ Bukovinian State Medical University, Forensic Medicine and Medical Law Department, Chernivtsi, Ukraine
} 


\section{Purpose}

The purpose of the study was to establish statistically significant criteria for differentiation of the cause of death in the case of AP and CMP by using azimuthal-invariant polarization Mueller-matrix microscopy of polycrystalline fractions of histological sections of organs and blood films of the human body.

\section{Materials and Methods}

The object of the study was histological sections of the brain, adrenal glands, myocardium, and polycrystalline blood films, selected from 135 corpses of both sexes, aged 18 to 71 years. All samples were divided into two experimental groups by cause of death: due to AP and CMP. BT samples from the dead persons due to coronary heart disease (CHD) were used for control (control group, $\mathrm{n}=45$ ).

The main principle of the study was the use of a model description of the structure of the polycrystalline component of blood films and histological sections of BT of human organs, which is considered as two components - isotropic and anisotropic or crystalline. (Ushenko et al., 2016).

The task of developing objective digital forensic criteria for differentiating the cause of death from AP or CMP is based on azimuthal-invariant Mueller matrix polarimetry of the polycrystalline component of BT and human fluids. The research methodology is illustrated by the following scheme (Figure 1).

\begin{tabular}{|c|c|c|}
\hline \multicolumn{3}{|c|}{$\begin{array}{l}\text { Figure 1: Structural-logical scheme of the method of azimuthal-invariant mapping of the degree of } \\
\text { crystallization of biological layers }\end{array}$} \\
\hline 1 & Source of optical sounding & $\begin{array}{l}\text { Gas helium-neon laser; } \\
\text { Wavelength } 0.6328 \mu \mathrm{m} \\
\text { Power } 10 \mathrm{~mW}\end{array}$ \\
\hline 2 & $\begin{array}{l}\text { The block forming the spatial } \\
\text { structure of the optical probe }\end{array}$ & Optical collimator forming a parallel laser beam with a cross-section $5 \mathrm{~mm}$ \\
\hline 3 & $\begin{array}{l}\text { Multichannel block forming } \\
\text { the polarization structure of } \\
\text { the optical probe }\end{array}$ & $\begin{array}{c}\text { The system of formation linear }\left(0^{\circ} ; 90^{\circ} ; 45^{\circ}\right) \text { and right-circular polarization } \\
\text { (linear polarizer (Achromatic True Zero-Order Waveplate) - quarter-wave plate } \\
\text { (B + W Kaesemann XS-Pro Polarizer MRC Nano)) }\end{array}$ \\
\hline 4 & Object block & Microscopic coordinate node \\
\hline 5 & $\begin{array}{l}\text { Block formation of } \\
\text { microscopic images }\end{array}$ & $\begin{array}{l}\text { Polarizing microlens (Nikon CFI Achromat P, working distance }-30 \mathrm{~mm} \text {, focal } \\
\text { distance - 50mm, NA }-0.1 \text {, magnification }-4 \mathrm{x} \text { ) }\end{array}$ \\
\hline 6 & $\begin{array}{l}\text { Block of multichannel } \\
\text { polarization filtration }\end{array}$ & $\begin{array}{c}\text { The transmission system linear }\left(0^{\circ} ; 90^{\circ} ; 45^{\circ} ; 135^{\circ}\right) \text { right- and left-circularly } \\
\text { polarized components of light oscillations }\end{array}$ \\
\hline 7 & $\begin{array}{l}\text { Block of sampling digital } \\
\text { microscopic images }\end{array}$ & $\begin{array}{c}\text { Digital CCD camera } \\
\text { (The Imaging Source DMK 41AU02.AS, monochrome 1/2 "CCD, Sony } \\
\text { ICX205AL (progressive scan); resolution - 1280x960, size light-sensitive area - } \\
\text { 7600x6200mkm; sensitivity - 0,05 lx, dynamic range - } 8 \text { bit, SNR - } 9 \text { bit) by } \\
\text { polarization microobjective } 7 \text { (Nikon CFI Achromat P, focal length - } 30 \mathrm{~mm} \text {, } \\
\text { numerical aperture - } 0.1 \text { increase - 4x) }\end{array}$ \\
\hline 8 & $\begin{array}{l}\text { Block of computer processing } \\
\text { of Mueller matrix polarimetry }\end{array}$ & Definition of statistical points of 1-4 orders \\
\hline
\end{tabular}

The experimental methodology of azimuth-invariant Mueller-matrix polarization microscopy includes the following steps:

- within each of the representative samples of BT Mueller-matrix invariant (MMI) maps of polycrystalline component of histological sections of internal organs and blood films were experimentally determined;

- the values of the statistical moments of 1-4 order $(S r, D p, A s, E k)$, which characterize the MMI size distributions for each individual sample of BT, were calculated;

- the average value and the error of the magnitude of each of the central statistical moments of 14 order were determined within the control and two experimental groups of BT;

- for each of the central statistical moments of 1 - 4 orders, which characterize MMI distributions, statistical reliability of differentiation of MMI maps of the polycrystalline component of histological sections of BT of internal organs and blood films was established;

- within the principles of evidence-based medicine, the operational characteristics of the force of the azimuthal-invariant Mueller-matrix polarization microscopy method were calculated: sensitivity, specificity, balanced accuracy. 
According to this algorithm, changes in the statistical moments of MMI distribution of BT preparations of the human body were determined: brain, liver, adrenal glands, myocardium, and polycrystalline blood films for both experimental and control groups.

\section{Histological sections of the brain.}

Figure 2 shows maps and histograms of the distributions of the MMI of the linear birefringence (LB) of histological sections of the brain from the experimental and control groups of samples.

Comparative analysis of the coordinate distributions of MMI of LB (Fig. 2) revealed significant differences in the ranges of its change and transformation of the topographic structure of Mueller-matrix maps of histological sections of the brain of dead from coronary heart disease, AP, and CMP.

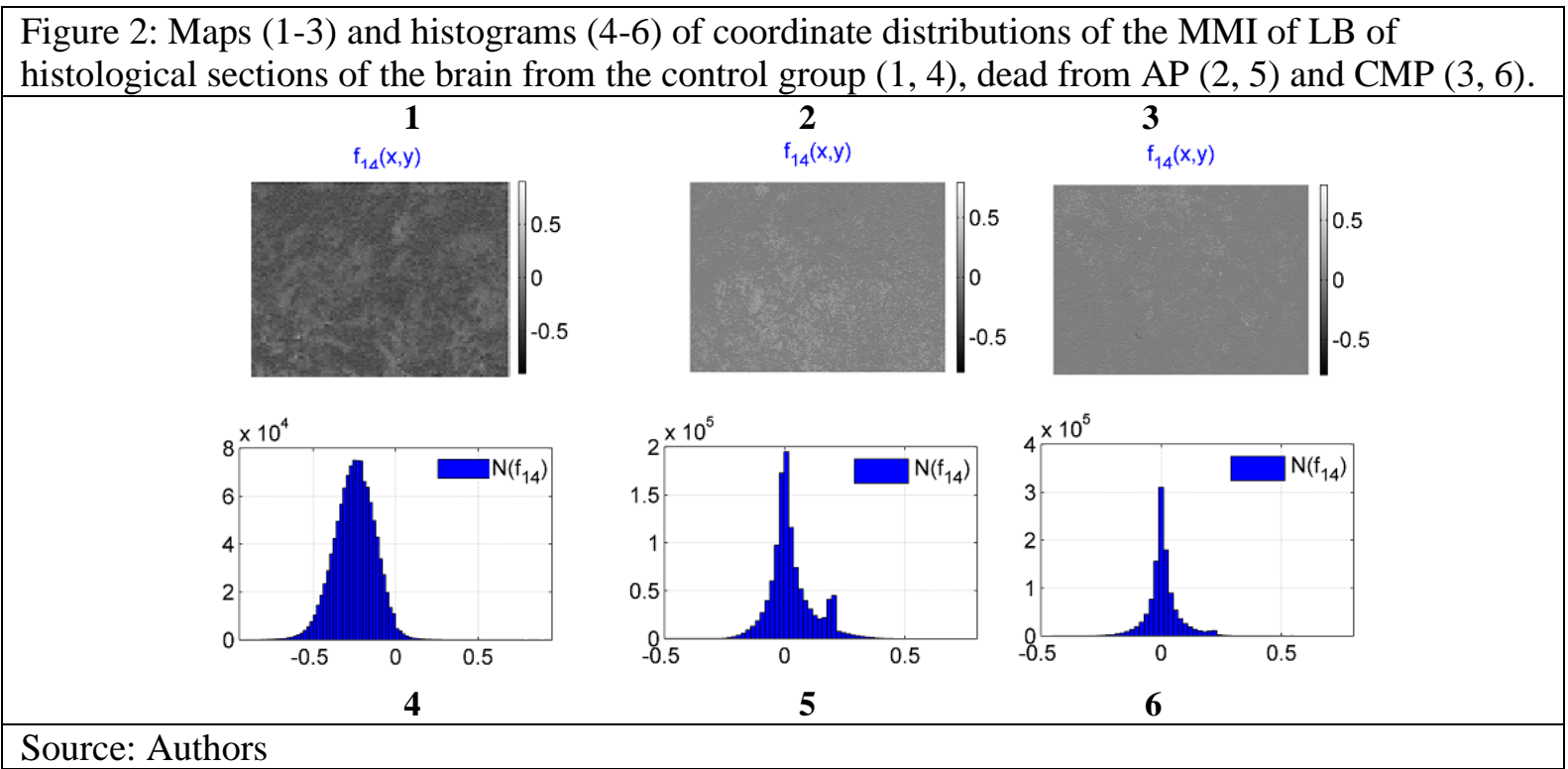

There is a tendency to decrease the value of statistical moments of the 1st and 2nd orders, as well as increasing the values of statistical moments of higher orders, which characterize the asymmetry and excess histograms of the distribution of MMI LD brain samples from deaths from an AP and CMP Table 1.

Table 1: Central statistical moments of the 1st - 4th orders characterize the coordinate distributions of the MMI LD of histological sections of the brain from the control and experimental groups.

\begin{tabular}{|c|c|c|c|}
\hline Sample & \multicolumn{3}{|c|}{ histological sections of the brain } \\
\hline statistical moments & group $1(n=45)$ & group $2(n=45)$ & group $3(n=45)$ \\
\hline average $(A v)$ & $0.14 \pm 0.007$ & $0.055 \pm 0.003$ & $0.025 \pm 0.002$ \\
\hline$\rho_{1} ; \rho_{2}$ & & $\rho_{l}<0.05$ & $\rho_{2}<0.05$ \\
\hline$\rho_{1} ; 2$ & & \multicolumn{2}{|c|}{$\rho_{1} ; 2<0.05$} \\
\hline dispersion $(D p)$ & $0.19 \pm 0.005$ & $0.09 \pm 0.004$ & $0.05 \pm 0.002$ \\
\hline$\rho_{1} ; \rho_{2}$ & & $\rho_{1}<0.05$ & $\rho_{2}<0.05$ \\
\hline$\rho_{1} ; 2$ & & \multicolumn{2}{|c|}{$\rho_{1} ; 2<0.05$} \\
\hline asymmetry (As) & $0.36 \pm 0.014$ & $0.71 \pm 0.034$ & $1.23 \pm 0.059$ \\
\hline$\rho_{1} ; \rho_{2}$ & & $\rho_{1}<0.05$ & $\rho_{2}<0.05$ \\
\hline$\rho_{1 ; 2}$ & & \multicolumn{2}{|c|}{$\rho_{1} ; 2<0.05$} \\
\hline $\operatorname{excess}(E k)$ & $1.36 \pm 0.061$ & $1.07 \pm 0.052$ & $0.86 \pm 0.042$ \\
\hline$\rho_{1} ; \rho_{2}$ & & $\rho_{l}<0.05$ & $\rho_{2}<0.05$ \\
\hline$\rho_{1 ; 2}$ & & \multicolumn{2}{|c|}{$\rho_{1} ; 2<0.05$} \\
\hline
\end{tabular}

Source: Authors

Statistical significance $\left(\rho_{1} ; \rho_{2} ; \rho_{1 ; 2}<0.05\right)$ of statistical moments characterize the distributions of MMD of LD of brain samples from all groups, for use in differentiating the cause of death.

Using the principles of information analysis of the results of statistical processing of the coordinate distributions of the MMI LD histological sections of the brain revealed a satisfactory level $(A s, E k \rightarrow 83 \%)$ of balanced accuracy of differential diagnosis of cases of AP and CMP, - table 2. 


Table 2: Operational characteristics of the strength of the Mueller-matrix polarimetry method.
\begin{tabular}{|c|c|c|c|c|c|c|c|c|}
\hline \multicolumn{2}{|c|}{ Sample } & \multicolumn{7}{c|}{ histological sections of the brain } \\
\hline$S t_{j=1,2,3,4}$ & $A v$ & \multicolumn{2}{c|}{$D p$} & \multicolumn{2}{c|}{$A s$} & \multicolumn{2}{c|}{$E k$} \\
\hline$S e, \%$ & $\mathrm{a}=33 ; \mathrm{b}=12$ & 73.3 & $\mathrm{a}=35 ; \mathrm{b}=10$ & 77.7 & $\mathrm{a}=39 ; \mathrm{b}=6$ & 86.6 & $\mathrm{a}=39 ; \mathrm{B}=6$ & 86.6 \\
\hline$S p, \%$ & $\mathrm{c}=33 ; \mathrm{d}=12$ & 73.3 & $\mathrm{c}=35 ; \mathrm{d}=10$ & 77.7 & $\mathrm{c}=35 ; \mathrm{d}=10$ & 77.7 & $\mathrm{c}=36 ; \mathrm{D}=9$ & 80 \\
\hline$A c, \%$ & $\mathrm{n}=45$ & 73.3 & $\mathrm{n}=45$ & 77.7 & $\mathrm{n}=45$ & 82.5 & $\mathrm{n}=45$ & 83.3 \\
\hline
\end{tabular}

Source: Authors

\section{Histological sections of the myocardium.}

Results of Mueller-matrix polarimetric mapping of histological sections of the myocardium from experimental and control groups are presented in Figure 3.

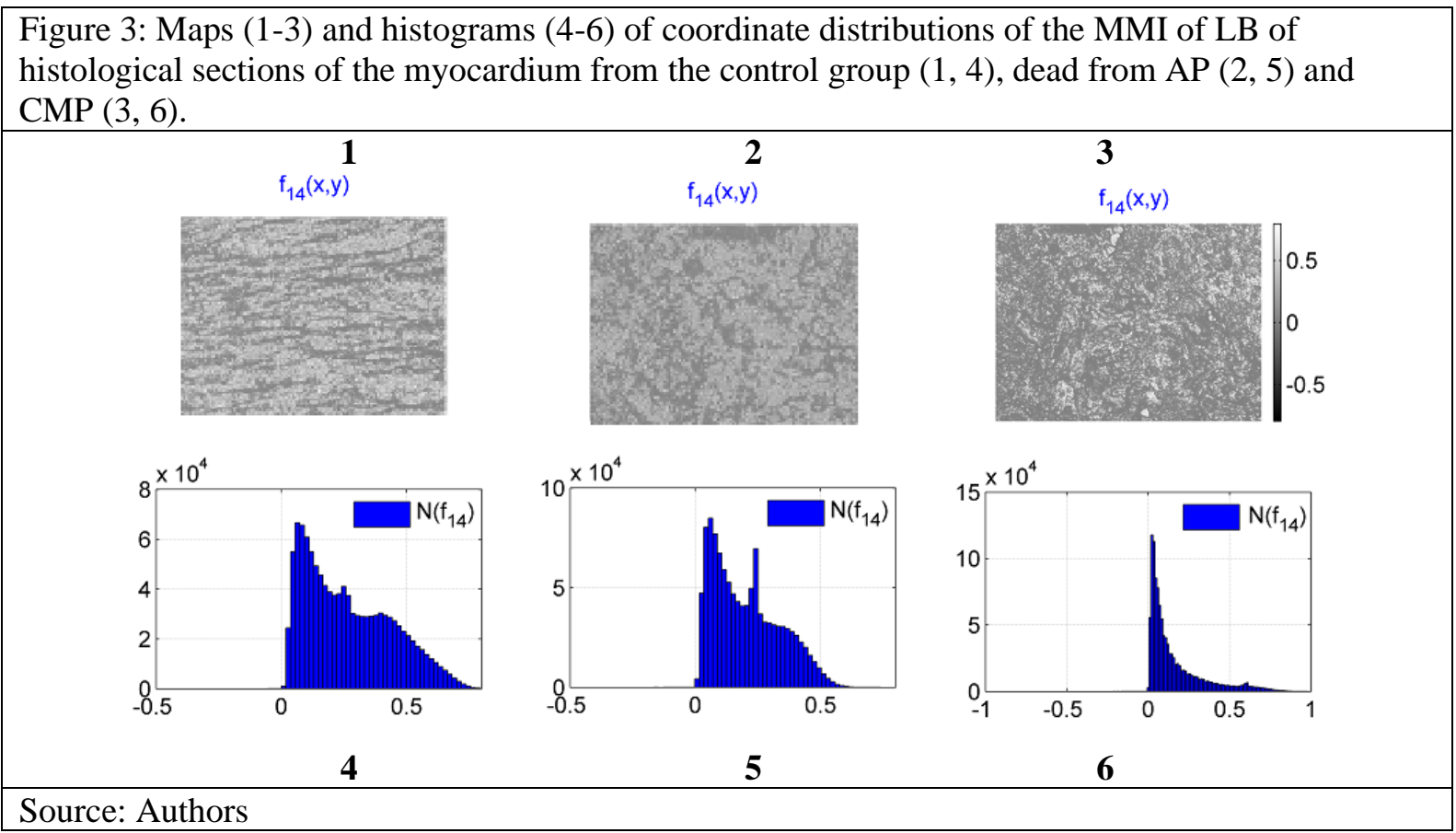

Mueller-matrix polarization mapping of fibrillar myosin networks of myocardial samples (Fig. 3) revealed significant differences between the ranges of variations of MMI LD values and the topographic structure of experimentally measured maps of MMI LD samples from CHD, AP, and CMP.

\begin{tabular}{|c|c|c|c|}
\hline Sample & \multicolumn{3}{|c|}{ histological sections of the myocardium } \\
\hline statistical moments & group $1(n=45)$ & group $2(n=45)$ & group $3(n=45)$ \\
\hline average $(A v)$ & $0.28 \pm 0.013$ & $0.17 \pm 0.008$ & $0.08 \pm 0.004$ \\
\hline$\rho_{1} ; \rho_{2}$ & & $\rho_{1}<0.05$ & $\rho_{2}<0.05$ \\
\hline$\rho_{1} ; 2$ & & \multicolumn{2}{|c|}{$\rho_{l ; 2}<0.05$} \\
\hline dispersion $(D p)$ & $0.39 \pm 0.017$ & $0.21 \pm 0.011$ & $0.095 \pm 0.005$ \\
\hline$\rho_{1} ; \rho_{2}$ & & $\rho_{1}<0.05$ & $\rho_{2}<0.05$ \\
\hline$\rho_{l ; 2}$ & & \multicolumn{2}{|c|}{$\rho_{1} ; 2<0.05$} \\
\hline $\operatorname{asymmetry}(A s)$ & $0.93 \pm 0.046$ & $1.38 \pm 0.065$ & $2.03 \pm 0.11$ \\
\hline$\rho_{1} ; \rho_{2}$ & & $\rho_{1}<0.05$ & $\rho_{2}<0.05$ \\
\hline$\rho_{1 ; 2}$ & & \multicolumn{2}{|c|}{$\rho_{1} ; 2<0.05$} \\
\hline $\operatorname{excess}(E k)$ & $0.66 \pm 0.031$ & $0.95 \pm 0.045$ & $1.81 \pm 0.092$ \\
\hline$\rho_{1} ; \rho_{2}$ & & $\rho_{1}<0.05$ & $\rho_{2}<0.05$ \\
\hline$\rho_{1 ; 2}$ & & \multicolumn{2}{|c|}{$\rho_{1 ; 2}<0.05$} \\
\hline
\end{tabular}

Degenerative-dystrophic changes of myocardial tissue correspond to a decrease in the magnitude of statistical moments of the 1st-2nd orders and an increase in statistical moments of the 3rd and 4th orders histograms of the distribution of MMI LD samples - table 3. 
Comparative analysis of the average (within representative samples) of the set of central statistical moments of the 1st - 4th orders revealed the diagnostic efficiency (statistical reliability $\rho 1 ; \rho 2 ; \rho 1 ; 2$ $<0.05$ ) of the method of azimuthal-invariant Mueller matrix microscopy in the differentiation of myocardial samples from all groups.

Table 4 shows the results of determining the operational characteristics of the force of the method of azimuthal-invariant Mueller-matrix polarimetry of histological sections of the myocardium.

\begin{tabular}{|c|c|c|c|c|c|c|c|c|}
\hline \multicolumn{2}{|c|}{ Sample } & \multicolumn{7}{|c|}{ histological sections of the myocardium } \\
\hline$S t_{j=1,2,3,4}$ & \multicolumn{2}{|c|}{$A v$} & \multicolumn{2}{|c|}{$D p$} & \multicolumn{2}{|c|}{$A s$} & \multicolumn{2}{|c|}{$E k$} \\
\hline$S e, \%$ & $a=36 ; b=9$ & 80 & $a=37 ; b=8$ & 82.2 & $\mathrm{a}=38 ; \mathrm{b}=7$ & 84.4 & $a=39 ; b=6$ & 86.6 \\
\hline$S p, \%$ & $\mathrm{c}=36 ; \mathrm{d}=9$ & 80 & $\mathrm{c}=25 ; \mathrm{d}=20$ & 80 & $\mathrm{c}=38 ; \mathrm{d}=7$ & 84.4 & $\mathrm{c}=38 ; \mathrm{d}=7$ & 84.4 \\
\hline$A c, \%$ & $n=45$ & 80 & $\mathrm{n}=45$ & 80.6 & $\mathrm{n}=45$ & 84.4 & $\mathrm{n}=45$ & 85.5 \\
\hline
\end{tabular}

Source: Authors

Information analysis of the results of statistical processing of the coordinate distributions of the MMI LD histological sections of the myocardium showed a satisfactory $(A v, D p \rightarrow 81 \%)$ and good (As, $E k \rightarrow 85 \%$ ) level of balanced accuracy of differential diagnosis of cases of alcohol and carbon monoxide poisoning.

\section{Histological sections of the adrenal glands.}

Figure 4 illustrates the results of azimuthal-invariant Mueller-matrix polarimetric mapping of the polycrystalline component of histological sections of the adrenal glands from the experimental and two control groups - coordinate (1-3) and statistical (4-6) distributions of the MMI LD.

Figure 4: Maps (1-3) and histograms (4-6) of coordinate distributions of the MMI of LB of histological sections of the adrenal glands from the control group $(1,4)$, dead from AP $(2,5)$, and

CMP $(3,6)$.

1

$f_{14}(x, y)$
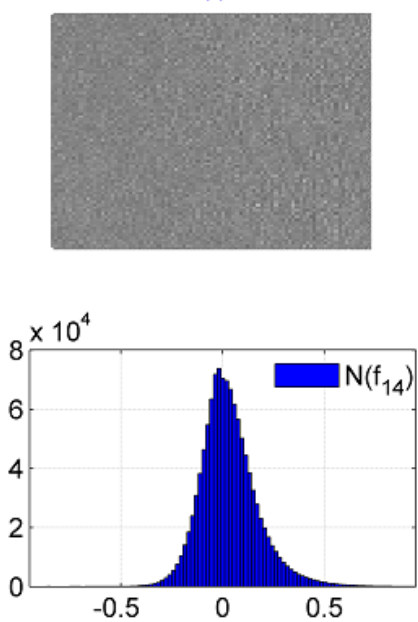

4
2

$\mathrm{f}_{14}(\mathrm{x}, \mathrm{y})$
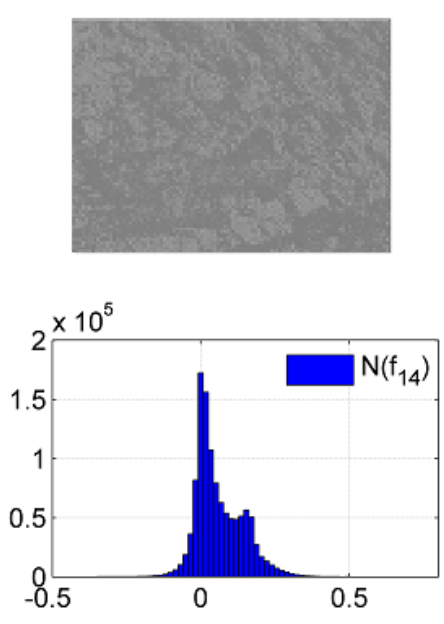

5
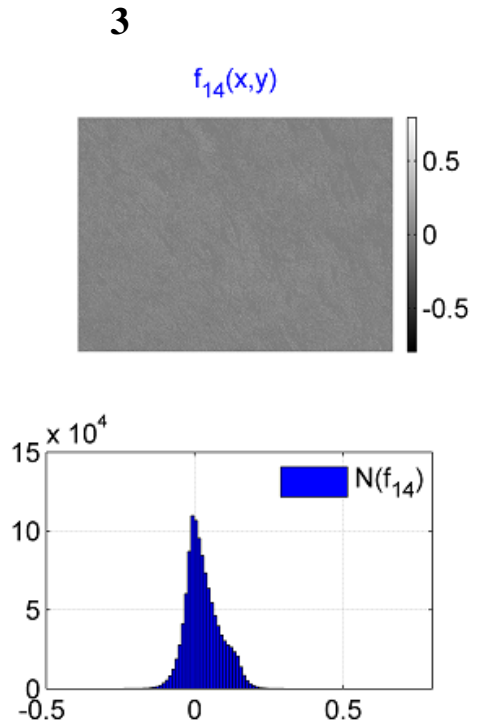

6

Source: Authors

Comparison of the topographic structure of LD MMI maps and histograms of its magnitudes revealed a scenario similar to Mueller-matrix polarimetric studies of the optically anisotropic component of histological sections of the brain (Fig. 2) and myocardium (Fig. 3): decrease of the magnitude and ranges of change of MMI LD, which are quantitatively manifested in the reduction of statistical moments of the 1st and 2nd orders, as well as in the growth of statistical moments of higher orders, - table 5.

Comparison of the average values of the average within the representative samples of histological sections of the adrenal glands revealed statistical inaccuracy $\left(\rho_{1} ; 2>0.05\right)$ in the differentiation of deaths from AP and CMP. 
Table 5: Central statistical moments of the 1st - 4th orders characterize the coordinate distributions of the MMI LD of histological sections of the adrenal glands from the control and experimental groups.

\begin{tabular}{|c|c|c|c|}
\hline Sample & \multicolumn{3}{|c|}{ histological sections of the adrenal glands } \\
\hline statistical moments & group $1(n=45)$ & group $2(n=45)$ & group $3(n=45)$ \\
\hline average $(A v)$ & $0.09 \pm 0.004$ & $0.07 \pm 0.003$ & $0,05 \pm 0,002$ \\
\hline$\rho_{1} ; \rho_{2}$ & & $\rho_{1}<0.05$ & $\rho_{2}<0.05$ \\
\hline$\rho_{1} ; 2$ & & \multicolumn{2}{|c|}{$\rho_{1} ; 2>0.05$} \\
\hline dispersion $(D p)$ & $0.14 \pm 0.006$ & $0.09 \pm 0.004$ & $0,08 \pm 0,004$ \\
\hline$\rho_{1} ; \rho_{2}$ & & $\rho_{1}<0.05$ & $\rho_{2}<0.05$ \\
\hline$\rho_{1} ; 2$ & & \multicolumn{2}{|c|}{$\rho_{1} ; 2<0.05$} \\
\hline $\operatorname{asymmetry}($ As) & $0.31 \pm 0.014$ & $0.62 \pm 0.031$ & $0,51 \pm 0,024$ \\
\hline$\rho_{1} ; \rho_{2}$ & & $\rho_{1}<0.05$ & $\rho_{2}<0.05$ \\
\hline$\rho_{1} ; 2$ & & \multicolumn{2}{|c|}{$\rho_{1} ; 2<0.05$} \\
\hline $\operatorname{excess}(E k)$ & $0.26 \pm 0.013$ & $0.81 \pm 0.042$ & $0,74 \pm 0,031$ \\
\hline$\rho_{1} ; \rho_{2}$ & & $\rho_{1}<0.05$ & $\rho_{2}<0.05$ \\
\hline$\rho_{1} ; 2$ & & \multicolumn{2}{|c|}{$\rho_{1} ; 2<0.05$} \\
\hline
\end{tabular}

Calculation of the mean values of dispersion, asymmetry, and excess, which characterize the distributions of MMI LD polycrystalline component of histological sections of the adrenal glands, provides statistical significance $\left(\rho_{1} ; \rho_{2 ;} \rho_{1} ; 2<0.05\right)$ use in the differentiation of causes of death of all groups.

The results of determining the strength of the method of azimuthal-invariant Mueller matrix microscopy of the optically anisotropic structure of samples of histological sections of the adrenal glands in the differentiation of cases of AP and CMP by determining the set of operational characteristics (sensitivity, specificity, and balanced accuracy) based on a statistical analysis of the coordinate distributions of the MMI LD are presented in table 6.

Table 6: Operational characteristics of the strength of the Mueller-matrix polarimetry method.

\begin{tabular}{|c|c|c|c|c|c|c|c|c|}
\hline \multicolumn{2}{|c|}{ Sample } & \multicolumn{4}{c|}{ histological sections of the adrenal glands } \\
\hline$S t_{j=1,2,3,4}$ & \multicolumn{2}{|c|}{$A v$} & \multicolumn{2}{c|}{$D p$} & \multicolumn{2}{c|}{$A s$} & & \multicolumn{2}{c|}{$E k$} \\
\hline$S e, \%$ & $\mathrm{a}=35 ; \mathrm{b}=10$ & 77.7 & $\mathrm{a}=36 ; \mathrm{b}=9$ & 80 & $\mathrm{a}=37 ; \mathrm{b}=8$ & 82.2 & $\mathrm{a}=38 ; \mathrm{b}=7$ & 84.4 \\
\hline$S p, \%$ & $\mathrm{c}=35 ; \mathrm{d}=10$ & 77.7 & $\mathrm{a}=35 ; \mathrm{b}=10$ & 77.7 & $\mathrm{c}=35 ; \mathrm{d}=10$ & 77.7 & $\mathrm{c}=36 ; \mathrm{d}=9$ & 80 \\
\hline$A c, \%$ & $\mathrm{n}=45$ & 77.7 & $\mathrm{n}=45$ & 78.85 & $\mathrm{n}=45$ & 79.85 & $\mathrm{n}=45$ & 82.7 \\
\hline
\end{tabular}

Source: Authors

Information analysis of the results of statistical processing of the coordinate distributions of the MMI LD of histological sections of the adrenal glands showed a satisfactory level of accuracy (As, $E k \rightarrow 80$ 83\%) of differential diagnosis of cases of AP and CMP poisoning values.

\section{Polycrystalline blood films.}

The results of the method of Mueller-matrix mapping of blood films from the control and two experimental groups are presented in Fig. 5.

Comparative analysis of the tomographic structure of Mueller-matrix maps of LB and histograms of the distributions of the MMI of LB are shown in the fragments of Figs. 5, found greater sensitivity of the method of azimuthal-invariant Mueller-matrix polarimetric mapping of networks of biological crystals of polycrystalline blood films to degenerative-dystrophic changes for cases of AP and CMP in comparison with similar studies of histological sections of the adrenal glands.

The data of statistical analysis presented in table 7 follows a significant level (statistical reliability) of differentiation of blood film samples from all groups based on the calculation of statistical moments of 1-4th orders, which characterize MMI LD maps of biochemical crystals of blood films.

Table 8 shows the values of operational characteristics of the strength of the method of azimuthalinvariant Mueller-matrix polarimetry of blood film samples in the differentiation of cases of AP and CMP, determined by information analysis. 


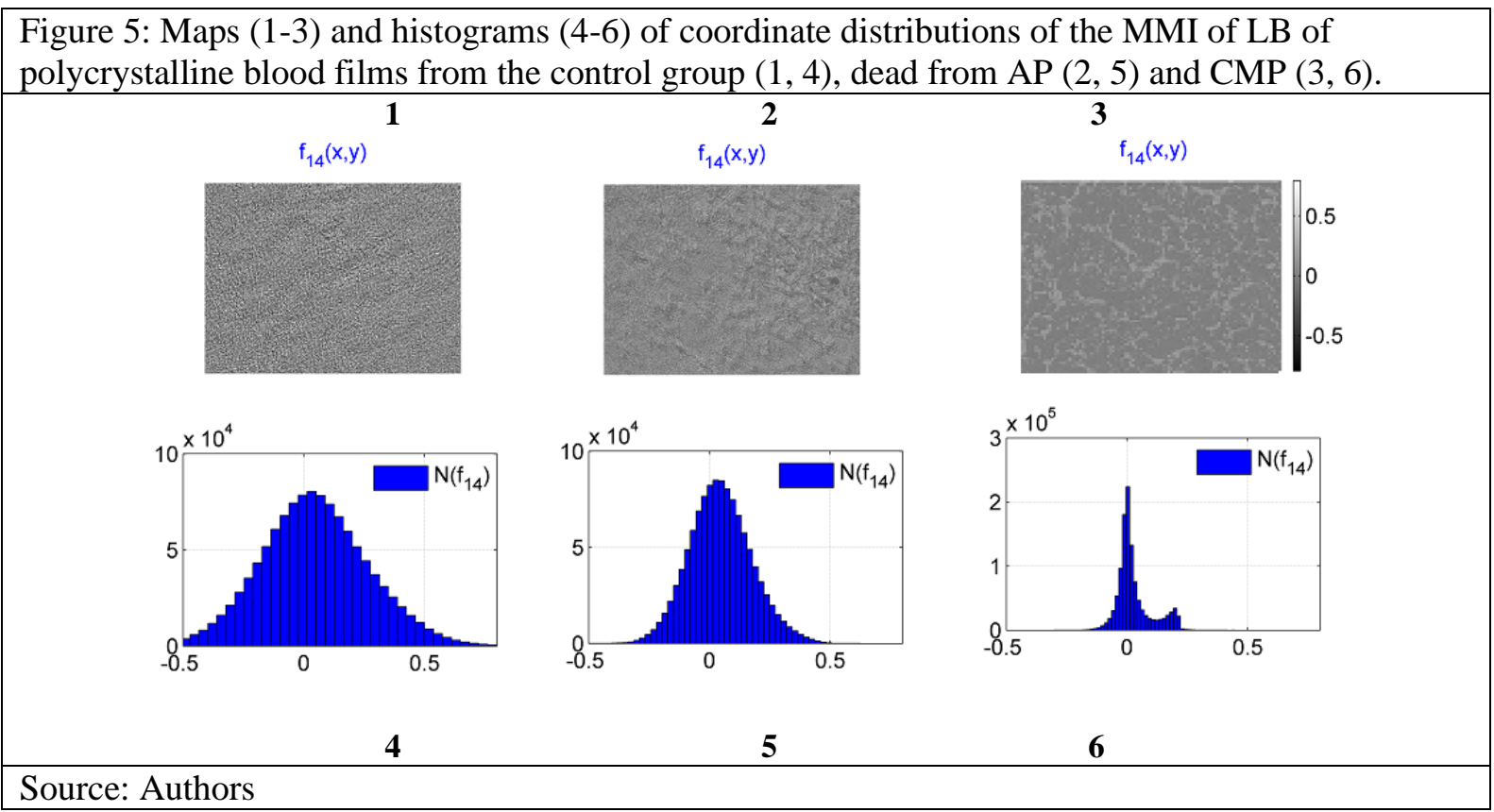

Table 7: Central statistical moments of the 1st - 4th orders, which characterize the coordinate distributions of the MMI LD of polycrystalline blood films from the control and experimental groups.

\begin{tabular}{|c|c|c|c|}
\hline Sample & \multicolumn{3}{|c|}{ polycrystalline blood films } \\
\hline statistical moments & group $1(n=45)$ & group $2(n=45)$ & group $3(n=45)$ \\
\hline average $(A v)$ & $0.08 \pm 0.004$ & $0.09 \pm 0.005$ & $0,075 \pm 0,004$ \\
\hline$\rho_{1} ; \rho_{2}$ & & $\rho_{1}<0.05$ & $\rho_{2}<0.05$ \\
\hline$\rho_{1} ; 2$ & & \multicolumn{2}{|c|}{$\rho_{1} ; 2>0.05$} \\
\hline dispersion (Dp) & $0.41 \pm 0.025$ & $0.18 \pm 0.0085$ & $0,095 \pm 0,005$ \\
\hline$\rho_{1} ; \rho_{2}$ & & $\rho_{1}<0.05$ & $\rho_{2}<0.05$ \\
\hline$\rho_{l} ; 2$ & & \multicolumn{2}{|c|}{$\rho_{1} ; 2<0.05$} \\
\hline $\operatorname{asymmetry}(A s)$ & $0.11 \pm 0.004$ & $0.21 \pm 0.009$ & $0,61 \pm 0,031$ \\
\hline$\rho_{1} ; \rho_{2}$ & & $\rho_{1}<0.05$ & $\rho_{2}<0.05$ \\
\hline$\rho_{1} ; 2$ & & \multicolumn{2}{|c|}{$\rho_{1} ; 2<0.05$} \\
\hline $\operatorname{excess}(E k)$ & $0.095 \pm 0.0049$ & $0.19 \pm 0.011$ & $1,11 \pm 0,094$ \\
\hline$\rho_{1} ; \rho_{2}$ & & $\rho_{1}<0.05$ & $\rho_{2}<0.05$ \\
\hline$\rho_{1} ; 2$ & & \multicolumn{2}{|c|}{$\rho_{1} ; 2<0.05$} \\
\hline
\end{tabular}

Table 8: Operational characteristics of the strength of the Mueller-matrix polarimetry method.

\begin{tabular}{|c|c|c|c|c|c|c|c|c|}
\hline \multicolumn{2}{|c|}{ Sample } & \multicolumn{4}{c|}{ polycrystalline blood films } \\
\hline$S t_{j=1,2,3,4}$ & \multicolumn{2}{|c|}{$A v$} & \multicolumn{2}{c|}{$D p$} & \multicolumn{2}{c|}{$E s$} & \multicolumn{2}{c|}{$E k$} \\
\hline$S e, \%$ & $\mathrm{a}=38 ; \mathrm{b}=7$ & 84.4 & $\mathrm{a}=37 ; \mathrm{b}=8$ & 82.2 & $\mathrm{a}=39 ; \mathrm{b}=6$ & 86.6 & $\mathrm{a}=40 ; \mathrm{b}=5$ & 88.8 \\
\hline$S p, \%$ & $\mathrm{c}=37 ; \mathrm{d}=8$ & 82.2 & $\mathrm{c}=37 ; \mathrm{d}=8$ & 82.2 & $\mathrm{c}=38 ; \mathrm{d}=7$ & 84.4 & $\mathrm{c}=39 ; \mathrm{d}=6$ & 86.6 \\
\hline$A c, \%$ & $\mathrm{n}=45$ & 83.3 & $\mathrm{n}=45$ & 82.2 & $\mathrm{n}=45$ & 85.5 & $\mathrm{n}=45$ & 87.7 \\
\hline
\end{tabular}

Source: Authors

Using the principles of evidence-based medicine based on the analysis of the results of statistical processing of the coordinate distributions of MMI LD polycrystalline blood films revealed a good ( $A s$, $E k \rightarrow 86 \%-88 \%)$ ) level of balanced accuracy of differential diagnosis of alcohol and carbon monoxide poisoning.

Results of information analysis of diagnostic possibilities of objective forensic differentiation of cases of AP and CVP by the method of multiparametric azimuthal-invariant Mueller-matrix polarimetry of linear birefringence of fibrillar networks of optically active molecular complexes of polycrystalline component of histological sections of the brain, myocardium, adrenal glands and polycrystalline blood films are presented in table 9. 
Table 9: Balanced accuracy of the method of multiparametric azimuthal-invariant Mueller-matrix polarimetry of linear birefringence in the differentiation of cases of alcohol and carbon monoxide poisoning.

\begin{tabular}{|c|c|c|}
\hline Biological layer & $A c, \%$ & Level \\
\hline histological sections of the brain & $\mathbf{8 3}$ & satisfactory \\
\hline histological sections of the myocardium & $\mathbf{8 5}$ & good \\
\hline histological sections of the adrenal glands & $\mathbf{8 3}$ & satisfactory \\
\hline polycrystalline blood films & $\mathbf{8 8}$ & good \\
\hline Source: Authors & & \\
\hline
\end{tabular}

\section{Conclusion}

A comprehensive experimental study of diagnostic efficiency in the differentiation of alcohol and carbon monoxide poisoning cases by the multiparametric method of azimuthal-invariant Mueller-matrix polarimetric microscopy of a linear birefringent polycrystalline component of histological sections of the brain, myocardium, and polycrystalline blood films was conducted.

The possibility of statistically significant differentiation of deaths from alcohol and carbon monoxide poisoning using azimuthal-invariant Mueller-matrix polarimetric microscopy of a linear birefringent polycrystalline component of histological sections of BT has been established.

This diagnostic algorithm provides a good level of accuracy in differentiating the cause of death in cases of examination of histological sections of the myocardium (Ac 85\%) and polycrystalline blood films (Ac $88 \%)$.

The results showed the effectiveness of the studied methodology and the prospect of further research in this direction.

\section{References}

Moon, J. M., Chun, B. J., Cho, Y. S., \& Mun, J. G. (2020). Does alcohol play the role of confounder or neuroprotective agent in acute carbon monoxide poisoning?. Clinical toxicology, 58(3), 161-170. doi.org/10.1080/15563650.2019.1625915

Sircar, K., Clower, J., Shin, M.K, Bailey, C., King, M., \& Yip, F. (2015). Carbon monoxide poisoning deaths in the United States, 1999 to 2012. The American journal of emergency medicine, 33(9), 1140-1145.

Simonsen, C., Thorsteinsson, K., Mortensen, R. N., Torp-Pedersen, C., Kjærgaard, B., \& Andreasen, J. J. (2019). Carbon monoxide poisoning in Denmark with focus on mortality and factors contributing to mortality. PLoS one, 14(1), e0210767.

Kim, H. H., Choi, S. C., Chae, M. K., \& Min, Y. G. (2018). Neuroprotective effect of ethanol in acute carbon monoxide intoxication: A retrospective study. Medicine (Baltimore),97(1), e9569. doi: 10.1097/MD.0000000000009569

Rose, J. J., Wang, L., Xu, Q., McTiernan, C. F., Shiva, S., Tejero, J., \& Gladwin, M. T. (2017). Carbon monoxide poisoning: pathogenesis, management, and future directions of therapy. American Journal of Respiratory and Critical Care Medicine, 195(5), 596-606. doi: 10.1164/rccm.201606-1275CI

Ushenko, A.G., Dubolazov, A.V., Ushenko, V.A., Ushenko, Yu.A., Pidkamin, L.Y., Soltys, I.V., Zhytaryuk, V.G., \&Pavlyukovich, N. Mueller-matrix mapping of optically anisotropic fluorophores of molecular biological tissues in the diagnosis of death causes. (2016). Proceedings of SPIE, 9971, Applications of Digital Image Processing, XXXIX, 99712L. doi: https://doi.org/10.1117/12.2237662

Ushenko, V. A., Prysyazhnyuk, V. P., Dubolazov, O. V., Karachevtsev, A. O., Olar, O. I., Olar, O. V., Marchuk, Yu. F., \& Savich, V. O.(2015). Polarization-correlation microscopy of human liquid polycrystalline films in infertility diagnosis. Proceedings of SPIE, 9599, Applications of Digital Image Processing, XXXVIII, 959922. doi: https://doi.org/10.1117/12.2187448 